\title{
Heavy Metals Concentrations in Deposited Dust of Typical Chinese Tree Species in Different Functional Areas in Nanjing
}

\author{
Jie Tang ${ }^{1,2 *}$, Yan Zha ${ }^{3}$, Yan Cheng ${ }^{4}$ \\ ${ }^{1}$ School of Resources and Environment, Anhui Agricultural University, Hefei, Anhui, China \\ ${ }^{2}$ Hefei Scientific Observing and Experimental Station of Agro-Environment, \\ Ministry of Agriculture, P.R. China \\ ${ }^{3}$ Co-Innovation Center for Sustainable Forestry in Southern China, Jiangsu Province Key Laboratory \\ of Ecological Engineering, Nanjing Forestry University, Nanjing, China \\ ${ }^{4}$ Hefei Environmental Monitoring Central Station, Hefei, Anhui, China
}

Received: 22 March 2018

Accepted: 12 July 2018

\begin{abstract}
Foliar dust passively adsorbs anthropogenic heavy metals (HM) present in the atmosphere and thus reduces the total suspended particle (TSP) level. Urban plants have been shown to reduce the atmospheric level of ambient particulate matter (PM) via foliar dust adsorption. We studied heavy metal concentrations in the foliar dust of three typical tree species in five functional areas of Nanjing city. The highest levels of $\mathrm{Cd}(19.89 \pm 4.56 \mathrm{mg} / \mathrm{kg}), \mathrm{Pb}(167.33 \pm 16.61 \mathrm{mg} / \mathrm{kg})$ and Cr $(197.42 \pm 13.96 \mathrm{mg} / \mathrm{kg})$ were found in the Traffic Area (TA), whereas the highest levels of $\mathrm{Cu}$ $(309.27 \pm 25.79 \mathrm{mg} / \mathrm{kg})$ and $\mathrm{Zn}(1036.88 \pm 52.77 \mathrm{mg} / \mathrm{kg})$ were found in the Industrial Area (IA). Significant differences were found between tree species. The amount of PM per unit leaf area generally decreased in this order: Cedrus deodara $>$ Pittosporum tobira $>$ Cinnamomum camphora. The highest mass percentages of large, coarse and fine PM were captured by C. camphora, P. tobira and C. deodara, respectively. A scanning electron microscope (SEM) was used to investigate the surfaces of the leaves, as well as the density and size of the stomata of each species. Our results suggest that an oily and coarse leaf surface is the most important factor facilitating PM accumulation, but large high-density stomata also enhance PM adsorption and thus favor HM accumulation in foliar dust. This study shows that the HM concentrations in foliar dust can act as an indicator of air pollution.
\end{abstract}

Keywords: heavy metals, foliar dust, air pollution, urban plants

*e-mail: ahnydx1989@163.com 


\section{Introduction}

The unprecedented economic development in China in recent years has been accompanied by unprecedented environmental changes. Particulate matter (PM) in the atmosphere can be utilized to characterize the environmental quality of urban areas [1-3]. The capacity of dust particles to carry pollutants depends largely on their particulate composition in terms of minerals and organic matter [4]. Heavy metals in dust can persist in urban environments, or they may be resuspended in the atmosphere and thus pose a threat to public health and ecosystems [5]. The sources of heavy metal pollutants include domestic waste, the chemical industry and transportation [6]. Most previous studies of heavy metal pollution have determined the concentrations, distributions and sources of heavy metals in roadside dust [7-9]. However, the presence of heavy metals in foliar dust is of greater concern because of the frequent hand-to-mouth activities of children, which increase their exposure to pollutants in dust. In addition, the height of roadside shrubs on which dust is deposited is often similar to that of children $(0.5-1.5 \mathrm{~m})$, and this similarity in height could be an important contributor to dust intake by children via direct inhalation [10].

Leaves are highly exposed to air pollution and purify air by absorbing atmospheric pollutants [11-12] such as trace elements, salts and pollens [13]. The leaves of tree species Robinia pseudoacacia and Taxus baccata have been used as indicators to assess the quality of air in urban environments [14-17]. The efficacy of removing pollutants from the air using plants depends on the particular type of tree canopy, branch density and leaf morphology $[2,11,18]$. Some species are more effective accumulators of PM because of the microstructure of their leaves [19]. For example, the needles of coniferous species produce a relatively thick epicuticular wax layer that favors PM accumulation. In addition, broadleaf species with rough leaf surfaces capture PM better than those with smooth leaf surfaces [11]. Knowledge of the factors that favor or inhibit accumulation of PM, including heavy metals, from the air on foliage is important for policymakers, farmers and citizens with the responsibility of protecting human health and the environment.

The aim of this study was to determine the concentration of heavy metals $(\mathrm{Cd}, \mathrm{Cr}, \mathrm{Cu}, \mathrm{Pb}$ and $\mathrm{Zn}$ ) in foliar dust and to measure the size of PM on the foliar surface. Scanning electronic microscopy (SEM) analysis was utilized to gain a better understanding of the role of trees in capturing atmospheric pollutants, and heavy metals in particular, in an area of Nanjing that has experienced rapid urbanization and industrialization in the last decade [20-21].

\section{Material and Methods}

\section{Sampling and Sample Preparation}

Three tree species that are widely planted in Nanjing, Cedrus deodara, Cinnamomum camphora and Pittosporum tobira, were selected for this study. Thirty foliar dust samples were collected from different functional areas in a highly urbanized region of Nanjing during August 2017. Samples were collected from five

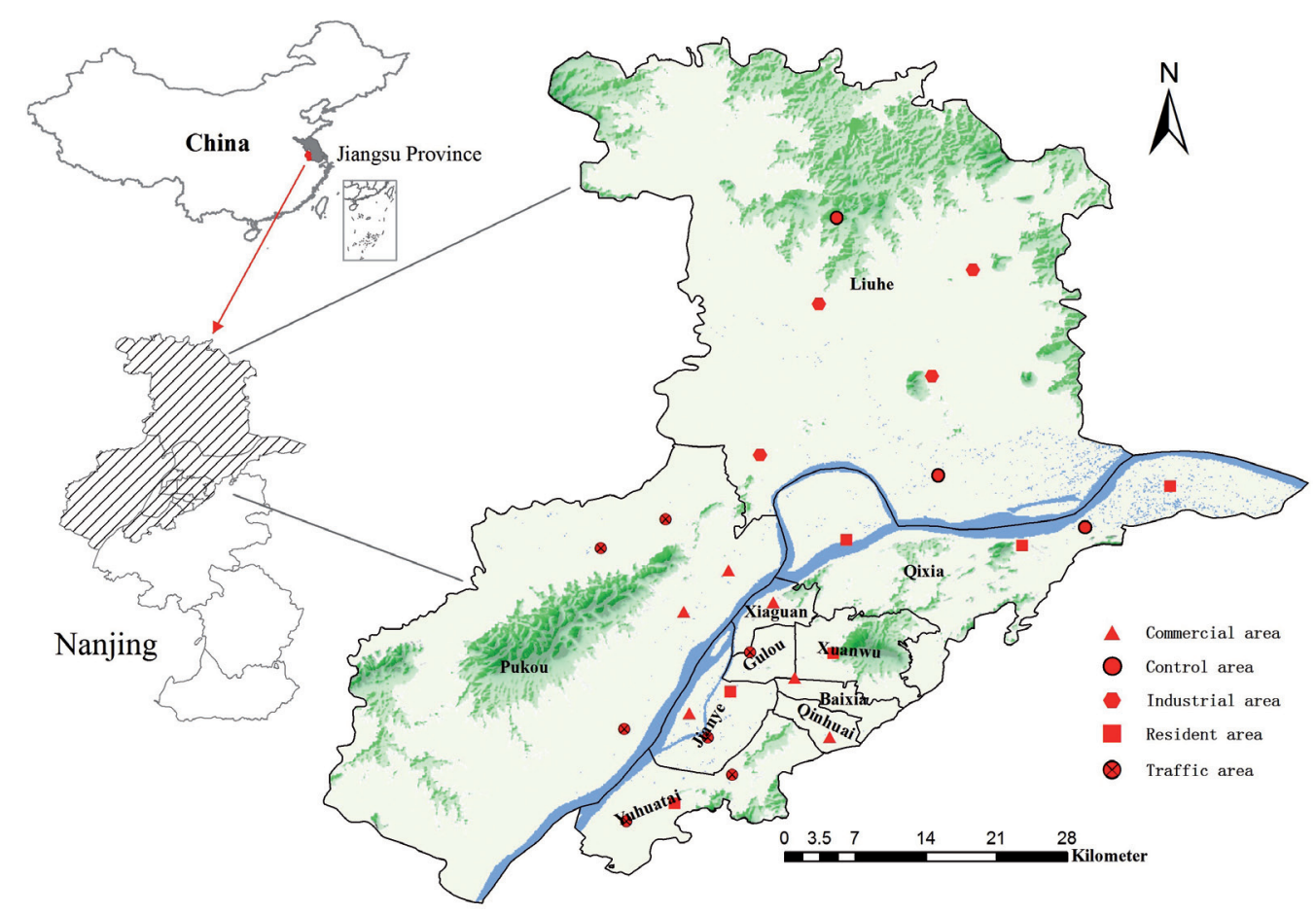

Fig. 1. Study area and sampling sites. 
types of urban area that have been identified as being characteristic of urban Nanjing: industrial areas (IA), residential areas (RA), commercial areas (CMA), traffic areas (TA) and control areas (CA). The locations of the selected urban areas are shown in Fig. 1. All samples were collected after at least 28 days had passed with no precipitation, because Liu et al. [22] showed that this practice led to the collection of leaves that had attained the maximum dust-retaining capability. Every sample consisted of approximately $800 \mathrm{~g}$ of leaves from mature and healthy trees collected at a height of 0.5-3 $\mathrm{m}$ above the ground. Eight individuals of each species were sampled. All leaf samples were collected from a single tree and stored at $4^{\circ} \mathrm{C}$ in a clean laboratory refrigerator prior to analysis. PM collected from the surface of the leaves was analyzed using the methods of Dzierżanowski et al [23].

\section{Heavy Metal Determination}

Concentrations of heavy metals $(\mathrm{Cd}, \mathrm{Cr}, \mathrm{Cu}, \mathrm{Pb}$ and $\mathrm{Zn}$ ) were determined using inductively coupled plasma mass spectrometry (ICP-MS). Before the assay, the dust samples were prepared as follows [24]. The leaves were washed using deionized water and placed into a 500-mL plastic container with $250 \mathrm{~mL}$ of Milli-Q water (Millipore, Bedford, MA, USA). The dust-containing suspension was filtered with $50 \mathrm{~mL}$ Milli-Q water, and $250 \mathrm{~mL}$ of the suspension was dried with a vacuum freeze-drier (Labconco, Kansas City, $\mathrm{MO}$, USA) for three days at $-83^{\circ} \mathrm{C}$ and stored at $-20^{\circ} \mathrm{C}$ until further extraction was performed. Approximately $0.5 \mathrm{~g}$ of the prepared dust sample was dried indoors at room temperature, and impurities such as tree leaves and stones were removed. The samples were ground to pass through a $0.15-\mathrm{mm}$ nylon sieve and mineralized on a hot plate in $\mathrm{HF}-\mathrm{HNO}_{3}-\mathrm{HClO}_{4} \quad(\mathrm{~V}: \mathrm{V}: \mathrm{V}=1: 1: 1)$, which was subsequently evaporated to dryness. The sample residue was dissolved in $\mathrm{HCl}$, after which the concentrations of trace metals in the resulting solution were determined by ICP-MS (Perkin Elmer Sciex DRCII, USA). The samples were analyzed in triplicate with standard reference materials and blanks. Before each test, all glassware was submerged in $0.1 \mathrm{M} \mathrm{HNO}_{3}$ for $48 \mathrm{~h}$, rinsed thoroughly with deionized water, and dried. All chemicals were of analytical grade. Reference samples obtained from the National Research Center for Certified Reference Materials (Beijing, China) were analyzed in parallel with each sample. The recoveries were between 84.72 and $107.25 \%$.

\section{Quantitative Analysis of PM}

The filters used for the analysis were first dried for 30 minutes at $60^{\circ} \mathrm{C}$ in a drying chamber (YB881-4, Suzhou, China). A balance and a humidity controller (WHD48-11, ACRELCo., Ltd., Jiangsu, China) were placed in the balancing box. To avoid electrostatic charges on the filters, they were first placed in a polytetrafluoroethylene (PTFE) balancing box under constant temperature $\left(25^{\circ} \mathrm{C}\right)$ and constant humidity $(40 \%)$ for 48 hours. Every sample of leaves was placed in a glass container with $250 \mathrm{~mL}$ of water and agitated for 60 seconds in order to wash off particles from the leaf surface. The three fractions of particulate matter were collected on filters: (1) large: $>10 \mu \mathrm{m},(2)$ coarse: 2.5-10 $\mu \mathrm{m}$ and (3) fine: 0.2-2.5 $\mu \mathrm{m}$. Samples were stored in paper bags in a dryer (DHG-9030A, Shanghai Jinghong Scientific Instrument Co., Ltd., Shanghai, China) at $60^{\circ} \mathrm{C}$ for 48 hours. Filters were weighed before and after particulate removal and storage using a balance sensitive (Sartorius Beijing Scientific Instrument Co., Ltd., Beijing, China) to $0.00001 \mathrm{~g}$ in order to calculate the mass of PM in each fraction of every sample.

\section{Scanning Electron Microscopy of the Leaves}

Scanning electron microscopy (FEI Quanta-200, USA) was used to investigate the surfaces of the leaves, as well as all the density and size of the stomata of each species. Small strips (approximately $1 \mathrm{~cm}^{2}$ ) were cut from the leaves and dehydrated in ethanol solutions $(30 \%, 50 \%, 70 \%, 90 \%$ and $100 \%)$ for $15 \mathrm{~min}$ each. The samples were gold-coated to enhance their electrical conductivity before analysis. Photographs were taken of randomly chosen spots at $1000 \times$ and $2000 \times$ magnification at $5 \mathrm{kV}$. Particle counting was performed using ImageJ software (National Institutes of Health, USA), according to the method described by Ottelé et al. [25].

\section{Statistical Analysis}

One-way analysis of variance (ANOVA) $(p<0.05)$ was applied to detect significantly different amounts of dust on leaf surfaces and significantly different concentrations of heavy metals in foliar dust. The LSD multiple comparison post hoc test was used to explore the significant differences identified by the ANOVA. Calculations were performed using SPSS version 17.0 (IBM Co., Armonk, NY, USA). Graphs were generated using Excel 2012 and Origin 9.0.

\section{Results and Discussion}

\section{Heavy Metal Concentrations in Foliar Dust in Urban Areas of Nanjing}

The heavy metal concentrations in the foliar dust from five different functional areas in Nanjing differed significantly (Table 1). The concentrations of the five determined elements in the foliar dust decreased in this order: $\mathrm{TA}>\mathrm{IA}>\mathrm{CMA}>\mathrm{RA}>\mathrm{CA}$. The highest average levels of $\mathrm{Cd}, \mathrm{Pb}$ and $\mathrm{Cr}$ were found in the TA and greatly exceed those in the foliar dust collected from other areas; this finding was attributed to vehicle emissions. The highest levels of $\mathrm{Cu}$ and $\mathrm{Zn}$ were found 


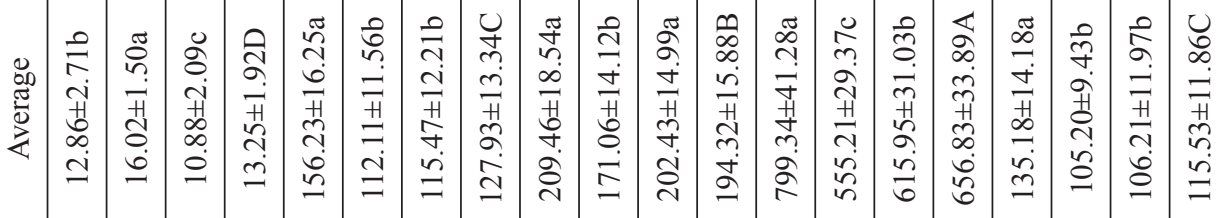

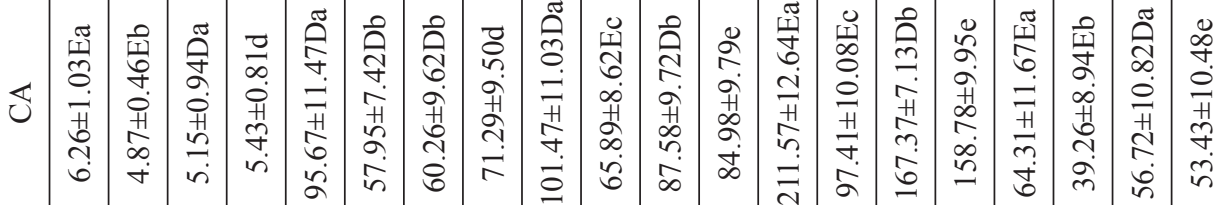

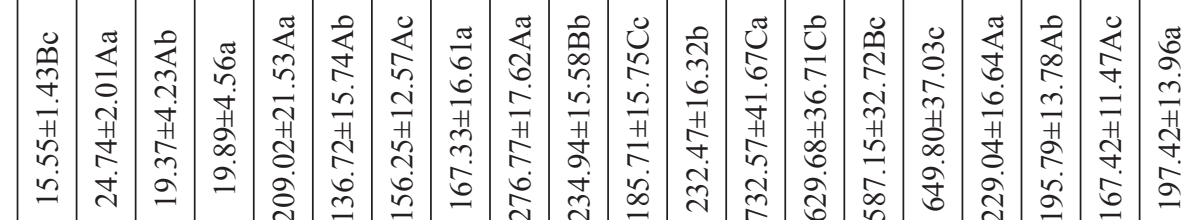

照

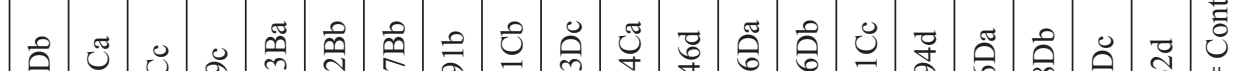

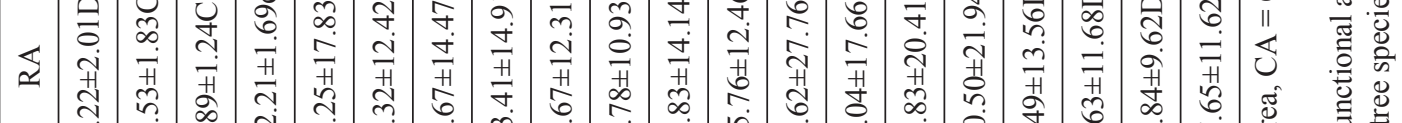

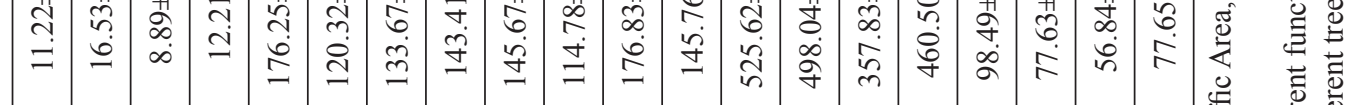

$\stackrel{\infty}{\mathscr{E}}$

$\stackrel{+}{\underline{m}}$

:

晃全

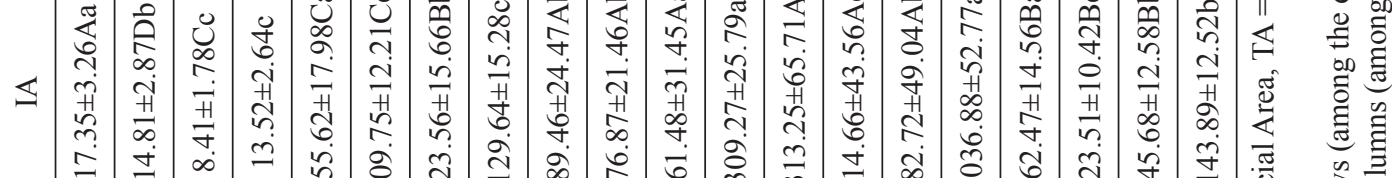

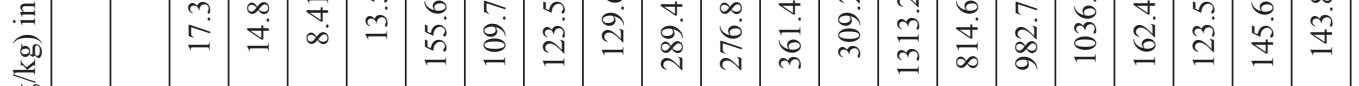

:

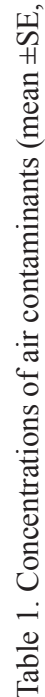

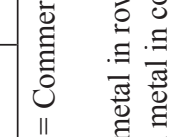


in the IA and greatly exceed those measured in the other functional areas; this finding was attributed to the incomplete combustion of petroleum and coal release in the IA. The Cd concentrations in the IA, RA, CMA, TA and CA were 237.19, 214.21, 266.67, 348.95 and 95.26 times higher, respectively, than the background soil concentration in Jiangsu Province, in which Nanjing is located (CNEMC, 1990). In contrast, the $\mathrm{Pb}$ concentrations in the IA, RA, CMA, TA and CA were $5.23,5.78,5.16,6.75$ and 2.87 times higher, respectively, than the background soil concentration in Jiangsu. It is worth noting that the heavy metal concentrations in Chinese cities vary greatly. For example, the average concentration of $\mathrm{Pb}$ in the TA and RA were higher than the average $\mathrm{Pb}$ concentration $(136.6 \mathrm{mg} / \mathrm{kg})$ in Shanghai [8], but lower than that in Huizhou $(486.0 \mathrm{mg} / \mathrm{kg}$ ) [7]. The $\mathrm{Cu}$ concentrations in the IA, RA, CMA, TA and CA were 9.60, 4.53, 6.18, 7.22 and 2.64 times higher, respectively, than the background soil concentrations in Jiangsu. The $\mathrm{Zn}$ concentrations in the IA, RA, CMA, TA and CA were 13.5, 6.00, 12.74, 8.46 and 2.07 times higher, respectively, than the background soil concentrations in Jiangsu. The average concentrations of $\mathrm{Cu}$ and $\mathrm{Zn}$ measured in our study greatly exceeded those reported in Debrecen, Hungary in 2011 [11]. The $\mathrm{Cr}$ concentrations in the IA, RA, CMA, TA and CA were $2.44,1.32,1.78,3.35$ and 0.91 times higher, respectively, than the background soil concentration in Jiangsu. The $\mathrm{Cr}$ concentrations in the selected areas were lower than those in Huizhou, an urban area of Hangzhou, China [7].

\section{Differences in Foliar Dust Heavy Metal Concentrations Among Species}

The concentrations of five elements in the foliar dust of three tree species were determined in the TA, IA, CMA, RA and CA (Table 1). In the case of Cd, the concentration in the foliar dust of $C$. deodara from the IA and CA was significant higher than that in the foliar dust of C. camphora or P. tobira from the IA and CA. The Cd concentration in the foliar dust of P. tobira from the RA and TA was significantly higher than that in the foliar dust of $C$. deodara or $C$. camphora from the RA and TA, which indicated that $\mathrm{Cd}$ was more easily captured by the leaves of P. tobira and $C$. deodara in comparison with those of $C$. camphora. The concentration of $\mathrm{Pb}$ in the foliar dust of $C$. deodara from the CMA was significantly higher than that in the foliar dust of C. camphora or P. tobira from all of the studied functional areas, with the exception of the CMA, which indicated that $C$. deodara was particularly capable as a remover of lead pollution from the atmosphere. The $\mathrm{Cu}$ concentration in the foliar dust of $P$. tobira from the IA and RA was significantly higher than that from the other tree species from the IA and RA, but the $\mathrm{Cu}$ concentration in the foliar dust of $C$. deodara was significantly higher than that in the foliar dust from the other tree species from the CMA, TA and CMA.
The $\mathrm{Zn}$ and $\mathrm{Cr}$ concentrations in the foliar dust of $C$. deodara were significantly higher than that from the other tree species in all areas. The mean concentration of $\mathrm{Cd}$ in the foliar dust of P. tobira was significantly higher than that of the foliar dust of $C$. deodara and C. camphora in all five functional areas. The $\mathrm{Pb}$ and $\mathrm{Cr}$ concentrations in the foliar dust of $C$. deodara was significantly higher than that in the foliar dust of $P$. tobira or C. camphora in all five functional areas, but there was no significant difference between $P$. tobira and $C$. camphora. The $\mathrm{Cu}$ concentrations in the foliar dust of $C$. deodara and P. tobira were significantly higher than that in the foliar dust of $C$. camphora in all five functional areas. The $\mathrm{Zn}$ concentration in the foliar dust of $C$. deodara was significantly higher than that in the foliar dust of $P$. tobira or C. camphora in all five functional areas, and the $\mathrm{Zn}$ concentration in the foliar dust of $P$. tobira was significantly higher than that in the foliar dust of $C$. camphora in all five functional areas. Our result indicated that the differences in heavy metal concentrations in foliar dust between species was significant, which is consistent with other conclusions $[26,27]$. The important traits of leaf micro morphology were the key factor that can influence air contaminant concentrations. Simon demonstrated that leaf micromorphology was important in the dust deposition, and which was further affected by high concentration of air contaminants [26]. TOMAŚEVIĆ and ANIĆIĆ also observed that most of the fine particles were deposited near the stomata, around the over, by which the physiological characteristics of leaves can be affected [27]. In our study we found that C. camphora was the most effective at capturing particulate matter and accumulating high heavy metal concentrations, which may be attributed to their coarse leaf surfaces.

\section{Differences in the Amount of PM Accumulation Among Species}

A comparison of the dust-retention abilities of different tree species in different functional areas was conducted. One-way ANOVA showed that the dust-retention properties of the three species of trees sampled differed significantly (Fig. 2). The maximum amount of total PM removed by $C$. deodara in the TA, IA, CMA, RA and CA was $112.36 \mu \mathrm{g} /$ $\mathrm{cm}^{2}, 75.12 \mu \mathrm{g} / \mathrm{cm}^{2}, 98.25 \mu \mathrm{g} / \mathrm{cm}^{2}, 117.42 \mu \mathrm{g} / \mathrm{cm}^{2}$ and $55.14 \mu \mathrm{g} / \mathrm{cm}^{2}$, respectively, which was significantly higher than that removed by $P$. tobira and C. camphora in each area. The average amount of $\mathrm{PM}>10 \mu \mathrm{m}$ in diameter retained on $C$. deodara was significantly higher than that retained on P. tobira or C. camphora, but there was no significant difference between $P$. tobira and C. camphora. The average amounts of PM 2.5-10 $\mu \mathrm{m}$ and $0.2-2.5 \mu \mathrm{m}$ in diameter retained on $C$. deodara were significantly higher than the corresponding amounts retained on $P$. tobira and C. camphora. The maximum amounts of $\mathrm{PM}>10 \mu \mathrm{m}, 2.5-10 \mu \mathrm{m}$ and $0.2-2.5 \mu \mathrm{m}$ in diameter were $70.87 \mu \mathrm{g} / \mathrm{cm}^{2}, 26.82 \mu \mathrm{g} / \mathrm{cm}^{2}$ 


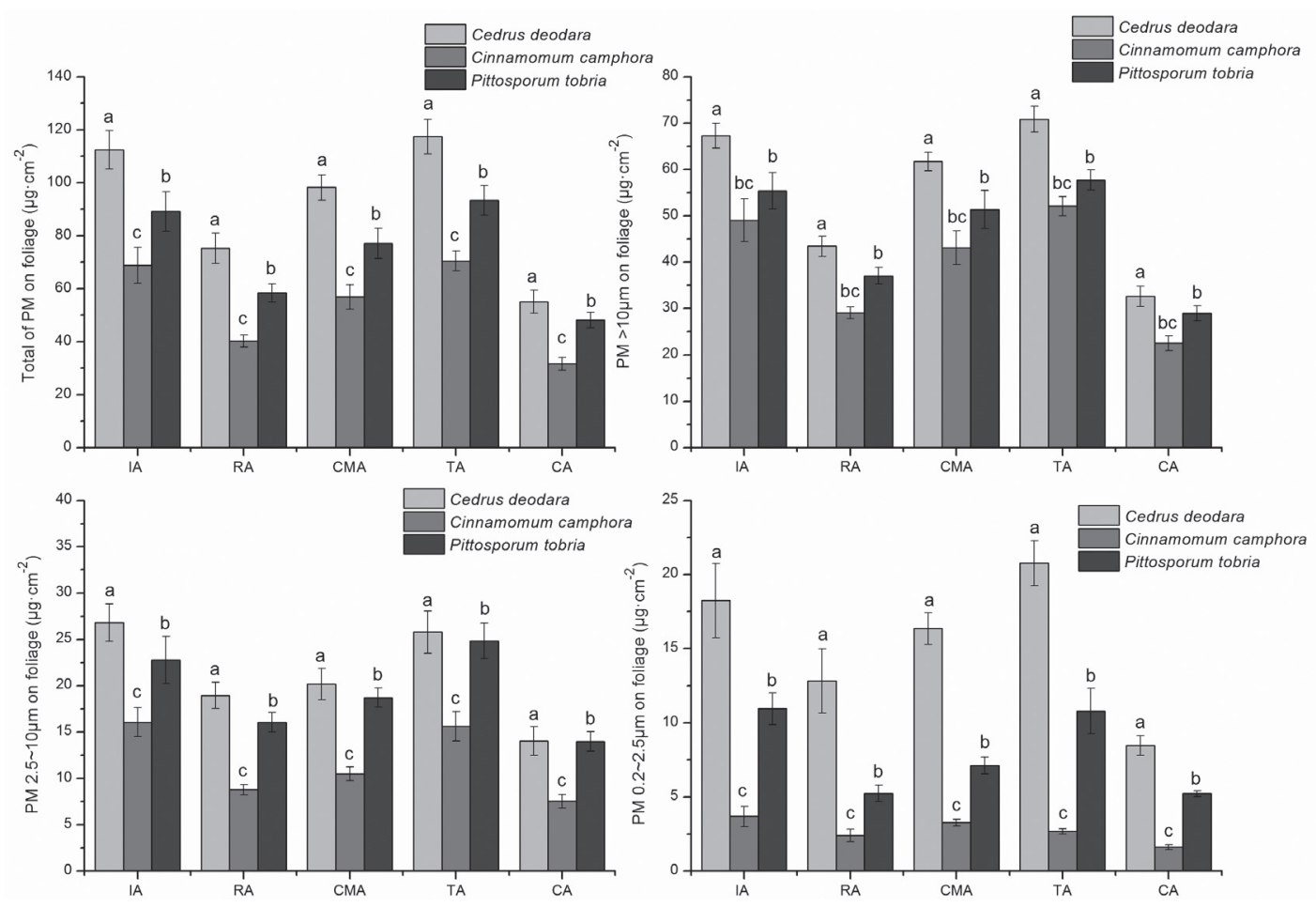

Fig. 2. The mass of PM in different sizes on foliage dust among tree species. Note: Different letters indicated significant difference $(\mathrm{p}<0.05)$.

and $20.77 \mu \mathrm{g} / \mathrm{cm}^{2}$, respectively. Based on the amounts of total PM, PM $>10 \mu \mathrm{m}, \mathrm{PM} 2.5-10 \mu \mathrm{m}$, and PM 0.2-2.5 $\mu \mathrm{m}$ on the leaf surfaces in each functional area, the areas were ranked as follows: TA $>\mathrm{IA}>\mathrm{CMA}>\mathrm{RA}>\mathrm{CA}$. The presence of large amounts of particles of different sizes in the TA were attributed to fine or ultrafine particles that originated from vehicle exhaust, which was in line with previous studies in Huizhou [7] and Guangzhou [22]. In addition, Song et al. reported fine or ultrafine particles that originated from vehicle exhaust and the burning of coal and biomass in an industrial area [1], which was consistent with our research. In contrast, the RA had less traffic and fewer anthropogenic activities, which led to relatively small amounts of aerial PM in this area.

\section{Mass Distribution Related to Size-Fractionated Particles Among Species}

Differences in PM accumulation among the three tested tree species are shown in Figs 3-5. Large PM
$(>10 \mu \mathrm{m})$ made a relatively large contribution to total PM (by wt), with average proportions of $60.0 \%, 72.9 \%$ and $62.8 \%$, respectively, for C. deodara, C. camphora and $P$. tobira, which indicated that $C$. camphora was most effective at capturing large particles on foliage. Coarse PM (2.5-10 $\mu \mathrm{m})$ made a moderate contribution to total PM (by wt), with average proportions of $26.6 \%$, $23.4 \%$ and $21.9 \%$, respectively, for $P$. tobira, $C$. deodara and $C$. camphora. These results showed that the largest proportion of coarse particles was captured by $P$. tobira. Fine PM $(0.2-2.5 \mu \mathrm{m})$ made a small contribution to total PM (by wt), with average proportions of 16.6\%, 5.21\% and $10.59 \%$, respectively, for C. deodara, C. camphora and $P$. tobira, which indicated that $C$. deodara was most effective at capturing large particles on foliage. Popek et al. found that large, coarse and fine PM deposited on foliage comprised $65 \%, 21 \%$ and $14 \%$ of the total PM, respectively [28]. Although fine particles represented only a small proportion of the captured particles, this accumulation was significant because fine particles are particularly harmful to human health.

Table 2. Comparison of stomatal features and PM2.5 amount on the leaf surface of the three investigated tree species in Nanjing.

\begin{tabular}{|c|c|c|c|c|c|}
\hline Tree species & $\begin{array}{c}\text { Stomata width } \\
(\mu \mathrm{m})\end{array}$ & $\begin{array}{c}\text { Stomata length } \\
(\mu \mathrm{m})\end{array}$ & $\begin{array}{c}\text { Stomata area } \\
\left(\mu \mathrm{m}^{2}\right)\end{array}$ & $\begin{array}{c}\text { Stomata density } \\
\left(\mathrm{number} / \mathrm{mm}^{2}\right)\end{array}$ & $\begin{array}{c}\text { PM2.5 } \\
\left(\mu \mathrm{g} / \mathrm{cm}^{2}\right)\end{array}$ \\
\hline Cedrus deodara & $22.14 \pm 0.76 \mathrm{a}$ & $15.3 \pm 0.25 \mathrm{a}$ & $265.91 \pm 2.76 \mathrm{a}$ & $314.37 \pm 3.52 \mathrm{a}$ & $17.16 \pm 0.78 \mathrm{a}$ \\
\hline Cinnamomum camphora & $12.52 \pm 0.14 \mathrm{~b}$ & $5.98 \pm 0.07 \mathrm{~b}$ & $58.77 \pm 1.35 \mathrm{c}$ & $205.26 \pm 2.86 \mathrm{bc}$ & $5.36 \pm 0.36 \mathrm{~b}$ \\
\hline Pittosporum tobria & $14.26 \pm 0.21 \mathrm{~b}$ & $7.16 \pm 0.14 \mathrm{~b}$ & $80.15 \pm 1.68 \mathrm{~b}$ & $238.1 \pm 2.57 \mathrm{~b}$ & $6.27 \pm 0.82 \mathrm{~b}$ \\
\hline
\end{tabular}

*Different letters indicate significant difference between means $(\mathrm{p}<0.05)$ 


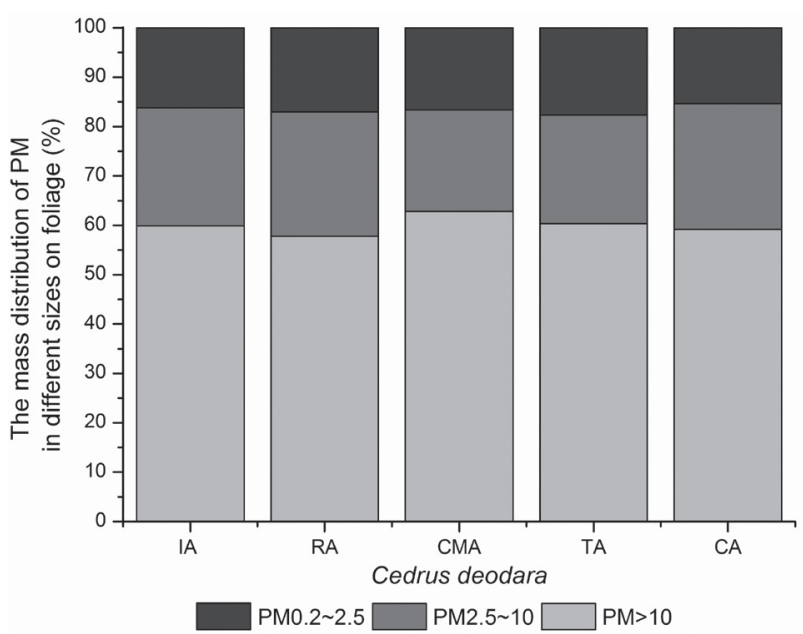

Fig. 3. The mass distribution of PM in different sizes on foliage dust of Cedrus deodara.

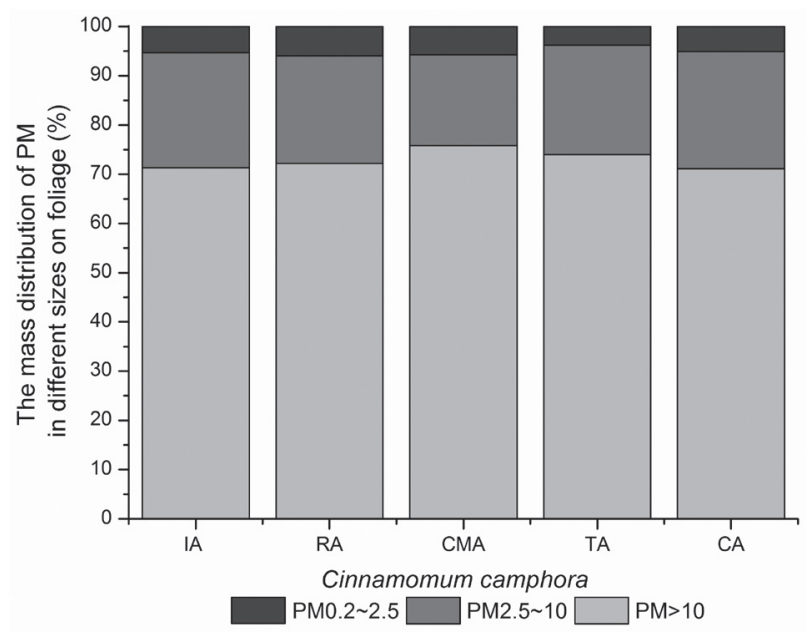

Fig. 4. The mass distribution of PM in different sizes on foliage dust of Cinnamomum camphora.

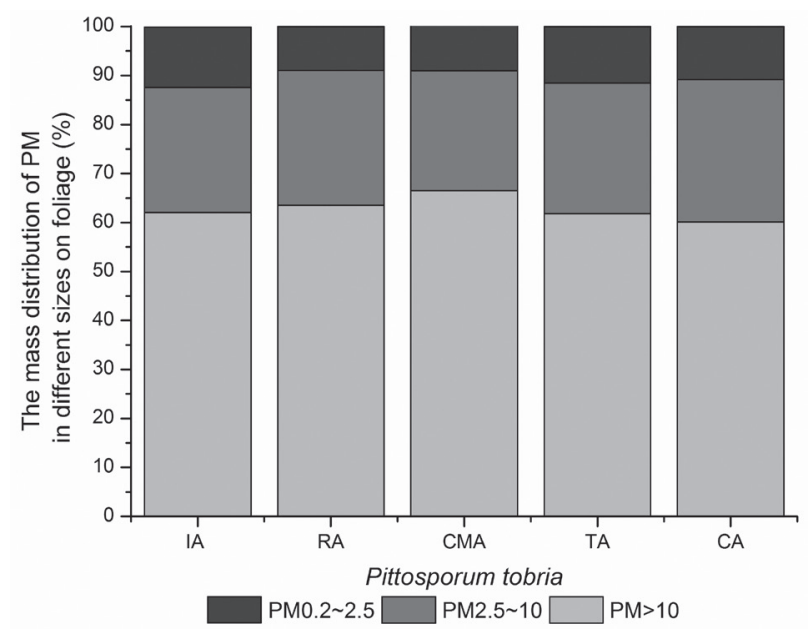

Fig. 5. The mass distribution of PM in different sizes on foliage dust of Pittosporum tobria.

\section{Effects of Morphological Structure Characteristics on Dust Adsorption}

The characteristics of the stomata of the three tree species selected for this study are shown in Table 2. The stomata width and length of $C$. deodara were significantly greater than those of the other two tree species, and no significant difference was observed between C. camphora and P. tobira for either measurement. The stomata density of $C$. deodara $\left(314.37 \pm 3.50 / \mathrm{mm}^{2}\right)$ was significantly higher than that of P. tobira $\left(205.26 \pm 2.86 / \mathrm{mm}^{2}\right)$ and C. camphora $\left(205.26 \pm 2.86 / \mathrm{mm}^{2}\right)$. The stomata area of the tested species was ranked in the following order (largest to smallest): C. deodara $\left(265.91 \pm 2.76 \mu \mathrm{m}^{2}\right)>P$. tobira $\left(80.15 \mu \mathrm{m}^{2)}>\right.$ C. camphora $\left(58.77 \mu \mathrm{m}^{2)}\right.$. The high particle capacity of $C$. deodara may be related to their high stomata density and large stomata area. Schönherr et al. indicated that high stomata density and large stomata openings can favor the capture of PM around $2.5 \mu \mathrm{m}$ in diameter [29], which is consistent with our research. In addition, the leaf structure influences the capacity to adsorb atmospheric PM. Foliage surface characteristics influence the ability of plants to retain atmospheric PM. Irregular spheres are clearly shown in Fig. 6. In terms of leaf shape, the needles of coniferous trees like $C$. deodara have a unique microstructure and a relatively thick epicuticular wax layer. Beckett et al. reported that most coniferous trees have slender needles that capture a relatively large amount of particles. The thick epicuticular wax layer on the adaxial needles of $C$. deodara (Fig. 6a) can produce oil that readily captures PM. For example, fly ash particles are easily adsorbed by leaves with oil, leaf hairs or mucilage [18]. Similar to our study, Simon et al. indicated that the roughness of a leaf surface was directly associated with the amount of dust deposited on it [11]. In addition, particle retention by $C$. deodara is enhanced by the rough adaxial surface and thicker epicuticular wax of its needles. The particle capture capacity of $C$. camphora was relatively weak because of its smooth foliar surface and shallow ditch-shaped tissues, which reduce the contact area available for particles (Fig. 6c). Particle retention by $P$. tobira was influenced by the irregularly corrugated shapes on the periphery of its stomata (Fig. 6f). We found that a greater amount of coarse PM was retained on the adaxial leaf surface in comparison with that retained on the abaxial leaf surface.

The deep grooves of $C$. deodara favor particle adsorption in comparison with the shallow grooves of P. tobira and C. camphora. Xie indicated that blade surface grooves with a depth of $5 \mu \mathrm{m}$ are ideal for retaining PM with a diameter of around $2.5 \mu \mathrm{m}$ [30]. The grooves of $P$. tobira are deeper than those of C. camphora, which favored the capture of fine particles by the abaxial leaves of P. tobira. As shown in Fig. 6a), the ditch-shaped grooves of the leaves of $C$. deodara increased their roughness, which enhanced their ability to capture particles. As shown in Fig. 6b), there were 


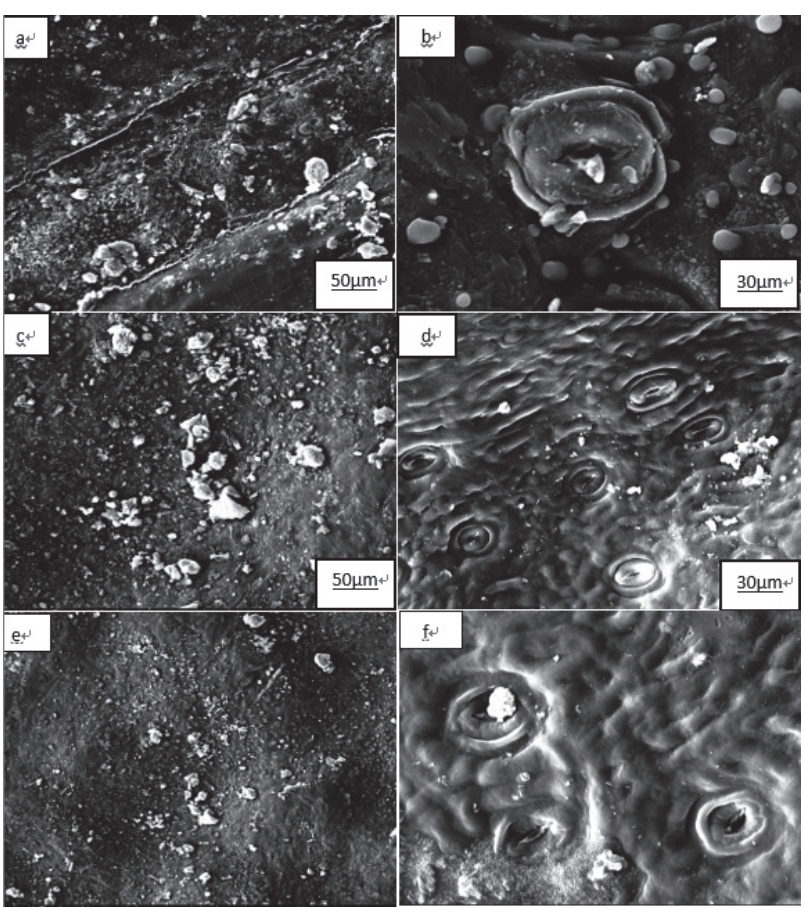

Fig. 6. The SEM images of particulate matter morphology on leaf surface of the three investigated tree species in Nanjing a,c,e) The adaxial leaf of C. Deodara, P. tobira, C. camphora. b) The abaxial leaf of C. Deodara, P. tobira, C.camphora.

more elliptical fine particles in the stomata center and surrounding area of $C$. deodara in comparison with the other tested species. The oily surface of the foliage of $C$. deodara captured more PM in comparison with the other tested leaves and prevented PM from being resuspended in the atmosphere.

\section{Relationship between the Particle Distribution and HM Concentrations}

The results of this study show that the particles in the foliar dust on different tree species differed with respect to size and heavy metal concentrations. $C$. deodara had the greatest amount of particles on the leaf surface in each of the investigated areas, as well as the greatest stomata density and area according to the SEM analysis. In addition, $C$. deodara removed more fine particles than did the other two species. Viklander et al. found that particles smaller than $75 \mu \mathrm{m}$ in street dust contained the greatest proportion of heavy metals, which indicated that grain size is an important factor influencing heavy metal accumulation [31]. The SEM images show that the particles on the leaf surface of $C$. deodara were mostly PM with a diameter around $2.5 \mu \mathrm{m}$. In contrast, the particles on the surfaces of C. camphora leaves consisted of particles larger than $10 \mu \mathrm{m}$, which can be observed clearly on the adaxial leaf surface. Similarly, $P$. tobira accumulated more coarse particles on its adaxial leaf surface. In this study, the capacity of tree species to accumulate the heavy metals decreased in the following order: C. deodara $>P$. tobira $>C$. camphora.
The different sizes of particles trapped on the surfaces of the leaves of the three tested tree species could explain why we found different concentrations of heavy metals on the surfaces of their leaves.

\section{Conclusions}

We studied foliar capture of PM with concomitant accumulation of heavy metals $(\mathrm{Cd}, \mathrm{Pb}, \mathrm{Cu}, \mathrm{Zn}$ and $\mathrm{Cr}$ ) by three tree species in Nanjing, China. The heavy metal concentration in foliar dust can be used as an indicator of atmospheric pollution in urban environments. We found significant differences among the tested tree species in terms of PM and heavy metal accumulation capacity. C. camphora, P. tobira and C. deodara were most effective at capturing large, coarse and fine PM, respectively. The most efficient species was $C$. deodara. Important traits that favored total PM accumulation were oily and coarse leaf surfaces, whereas the capture of fine PM was enhanced by large stomata area and high stomata density. The removal of PM by tree species in this study provides evidence to assist environmental planners in selecting suitable tree species to reduce PM and heavy metal contaminants in the atmosphere.

\section{Acknowledgements}

This study was supported by the Hefei Scientific Observing and Experimental Station of AgroEnvironment, Ministry of Agriculture, P.R. China, and funded by the University Science Research Project of Anhui Higher Education Institutions (KJ2016A234).

\section{Conflict of Interest}

The authors declare no conflict of interest.

\section{References}

1. SONG Y.S., MAHER B.A., LI F., WANG X.K., SUN X., ZHANG H.X.Particulate matter deposited on leaf of five evergreen species in Beijing China:Source identification and size distribution. Atmospheric Environment. 105, 53, 2015.

2. MO L., MA Z.Y., XU Y.S., SUN F.B., LUN X.X., LIU X.H., CHEN J.G., YU X.X. Assessing the capacity of plant species to accumulate particulate matter in Beijing, China. Plos One. 1-18, 2015.

3. XIE B.Z., WANG H.X., YANG J., WANG Y.G., SHI H. Retention capability of PM2.5 and It's explanation by leaf surface Micro-structure of common board-leaved tree species in Beijing. Acta Botanica Boreali-Occidentalia Sinica. 34 (12), 2432, 2014.

4. GUNAWARDNA C., GOONETILLEKE A., EGODAWATTA P., DAWES L., KOKOT S. Source characterization of road dust based on chemical and mineralogical composition. Chemosphere. 87, 163, 2012. 
5. LI X.D, PONG C, LIU P.S. Heavy metal contamination of urban soils and street dust in Hong Kong. Applied Geochemistry, 16, 1361, 2001.

6. CHEN X., XIA X.H., ZHAO Y., ZHANG P. Heavy metal concentrations in roadside soils and correlation with urban traffic in Beijing China. Journal of Hazardous Materials. 181 (1), 640, 2010.

7. QIU Y., GUANG D.S., SONG W.W., HUANG K.Y. Capture of heavy metals and sulfur by foliar dust in urban Huizhou, Guangdong Province, China.Chemosphere. 75, 447, 2009.

8. YIN R.J., WANG D.Q., DENG H.G.,SHI R.H.,CHEN Z.L. Heavy metal contamination and assessment of roadside and foliar dust along the outer-ring highway of Shanghai, China. Journal of Environmental Quality. 42, 1724, 2013.

9. SOLTANI N., KESHAVARZI B, MOORE F. TAVAKOL T., LAHIJANZADEH A.R., JAAFARZADEH N., KERMANI M. Ecological and human health hazards of heavy metals and polycyclic aromatic hydrocarbons (PAHs) in road dust of Isfahan metropolis, Iran. Science of the Total Environment. 505, 712, 2015.

10. SHI G.Z., CHEN C. Bi, Y. LI J. TENG L. WANG., XU S. Comprehensive assessment of toxic metals in urban and suburban street deposited sediments (SDSs) in the biggest metropolitan area of China. Environmental Pollution. 158, 694, 2011.

11. SIMON E., BRAUN M., VIDIC A., BOGYÓ D., FÁ BIÁN I., TÓTHMÉRÉSZ B. Air pollution assessment based on elemental concentration of leaves tissue and foliage dust along an urbanization gradient in Vienna. Environmental Pollution. 159, 1229, 2011.

12. ZHOU Z.X., SHAO T.Y., WANG P.C., GAO C., XU Y.R., GUO E.X., XU L.H., YE Z.Q. PENG X.M., YU C.J. The spatial structures and the dust retention effects of greenland types in the workshop district of Wuhan Iron and Steel Company. Acta Ecologica Sinica. 22, 2036, 2010.

13. RAM S.S., MAJUMDAR S., CHAUDHURI, P., CHANDA S., SANTRA S.C., MAITI PK., SUDARSHAN, M., CHAKRABORTY A. Plant canopies:bio-monitor and trap for re-suspended dust particulates contaminated with heavy metals. Mitigation and Adaptation Strategies for Global Change. 19 (5), 499, 2014.

14. TEPER E. Dust-particle migration around flotation tailings ponds: pine needles as passive samplers. Environmental Monitoring and Assessment 154, 383, 2009.

15. PALOWSKI B., MALKOWSKA E., KURTYKA R., SZYMANOWSKA J., GUCWA E., MAŁKOWSKI Ł., WOŹNICA A., MAŁKOWSKI E.Bioaccumulation of Heavy Metals in Selected Organs of Black Locust (Robinia pseudoacacia) and their Potential Use as Air Contamination Bioindicators. Polish Journal of Environmental Studies. 25, 2081, 2016.

16. SAMECKA A., STANKIEWICZA A., KOLONA K., KEMPERSB A.J.. Self-organizing feature map (neural networks) as a tool to select the best indicator of road traffic pollution (soil, leaves or bark of Robinia pseudoacacia L.). Environmental Pollution. 157, 2061, 2009.

17. SAMECKA A., KOLON K., KEMPERS A.Taxus baccata as a Bioindicator of Urban Environmental Pollution. Polish Journal of Environmental Studies. 20, 1021, 2011.
18. FREER-SMITH P.H., HOLLOWAY S., GOODMAN A. The uptake of particulates by an urban woodland: site description and particulate composition. Environmental Pollution. 95 (1), 27, 1997.

19. BECKETT K.P., FREE-SMITH P.H., TAYLOR G. The capture of particulate pollution by trees at five contrasting UK urban sites. Arboricultural Association Journal. 24 (2-3), 209, 2000.

20. YUAN L., YIN Y., LI Q., XIAO H., LI L. Aerosol concentration variation in Nanjing during Asian Youth Games and the relationship between aerosol concentration and visibility. Environmental Science. 35 (11), 4052, 2014 [In Chinese].

21. LI X.X., KONG S.F., YIN Y., LI L., YUAN L., LI Q., XIAO H., CHEN K. Polycyclic aromatic hydrocarbons (PAHs) in atmospheric PM2.5 around 2013 Asian Youth Games period in Nanjing. Atmospheric Research. 174-175, $85,2016$.

22. LIU L., GUAN D.S., PEART M.R. The morphological structure of leaves and the dust-retaining capability of afforested plants in urban Guangzhou, South China. Environmental Science and Pollution Research. 19 (8), 3440, 2012.

23. DZIERŻANOWKI K., POPEK R., GAWROŃSKA H., SEABØ A., GAWROŃSKA S.W. Deposition of particulate matter of different size fractions on leaf surfaces and in waxes of urban forest species. International Journal of Phytoremediation. 13, 1037, 2011

24. ZHA Y., LIU X., TANG J., ZHANG Y.L. PAHs in Foliage Dust of Typical Tree Species with Urbanization Gradient in Nanjing, China. Polish Journal of Environmental Studies. 27, 1359, 2018.

25. OTTELÉ M., BOHEMEN H.D.V., FRAAIJ A.L.A. Quantifying the deposition of particulate matter on climber vegetation on living walls. Ecological Engineering. 36, 154, 2010.

26. SIMON E., BARANYAI E., BRAUN M. CSERHÁTI C., FÁBIÁN I., TÓTHMÉRÉSZ B. Elemental concentrations in deposited dust on leaves along an urbanization gradient. Science of the Total Environment. 490, 514, 2014.

27. TOMAŚEVIĆ M., ANIĆIĆ M. Trace element content in urban tree leaves and SEX-EDAX characterization of deposited particles. Facta universitatis - series. Physical Chemistry Technology. 8, 1, 2011.

28. POPEK R., GAWROŃSKA H., WROCHNA M., GAWROŃSKI S.W., SEABØ A. Particulate matter on foliage of 13 woody species: Deposition on surfaces and phytostabilisation in waxes a 3 -year study. International Journal of Phytoremediation. 15, 245, 2013.

29. SCHÖNHERR J., LUBER M. Cuticular penetration of potassium salts: Effects of humidity, anions and temperature. Plant and Soil. 236, 117, 2001.

30. XIE B.Z., WANG H.X., YANG J., WANG Y.G., SHI H. Retention capability of PM2.5 and It's explanation by leaf surface Micro-structure of common board-leaved tree species in Beijing. Acta Botanica Boreali-Occidentalia Sinica. 34 (12), 2432, 2014.

31. VIKLANDER M. Particle size distribution and metal content in street sediments. Journal of Environmental Engineering, 124 (8), 761, 1998. 
